Brit. J. industr. Med., 1965, 22, 204.

\title{
RESPIRATORY FUNCTION AND SYMPTOMS IN ROPE MAKERS
}

\author{
BY \\ C. B. MCKERROW, J. C. GILSON, R. S. F. SCHILlING, and J. W. SKIDMORE \\ From the Pneumoconiosis Research Unit, Llandough Hospital, Penarth, Glam.
}

(RECEIVED FOR PUBLICATION MAY 13, 1965)

\begin{abstract}
This paper gives the results of a small environmental, symptomatic, and respiratory function study of byssinosis in a rope factory. An attempt was made to relate the changes in ventilatory function during the working day to the differing dust concentrations within the factory. The tests used included the forced expiratory volume, the forced vital capacity, and, in half the subjects, other derivatives of the forced expiratory spirogram. The inspiratory airways resistance was measured by the interrupter technique.

Measurements were made at the beginning and end of a working shift on either a Monday or a Tuesday in 44 subjects, of whom 22 were in a relatively dusty part of the factory and 14 , involved in making wire rope, were exposed to very little dust.

None of the subjects had symptoms of byssinosis, but significant falls were found in the F.E.V.1.0, F.V.C., and other derivatives of the forced expiratory spirogram in those in the dusty parts of the factory. There was some evidence that the peak flow rate, the maximal mid-expiratory flow, and similar indices might be a little more sensitive as measures of the acute changes in ventilatory capacity during the day than the F.E.V $\cdot_{\cdot 1 \cdot 0}$ and F.V.C. There were no significant changes in the airways resistance by the interrupter technique but the results were rather variable.

The fall in ventilatory capacity during the day was not greater in those with symptoms of chronic cough and sputum than in those without, nor did it seem to be related to smoking, but the number of subjects studied was small.
\end{abstract}

For at least 250 years it has been known that those who process flax and hemp may suffer from a respiratory disease. Ramazzini (1713) described their condition and stated that flax seemed more injurious than hemp. In recent years flax byssinosis has been described in Ulster by Smiley (1961) and Elwood, Pemberton, Merrett, Carey, and McAulay (1965), and in Scotland by Mair, Smith, Wilson, and Lockhart (1960). The symptoms are similar to those of cotton byssinosis (Schilling, Hughes, DingwallFordyce, and Gilson, 1955).

The incidence of disease in hemp and sisal workers has not been so fully investigated, but it is generally believed to be low. Stott (1958) and Gilson, Stott, Hopwood, Roach, McKerrow, and Schilling (1962) found no evidence that sisal dust causes byssinosis and, although the disease has been known to occur in workers handling soft hemp derived from the stem of the plant, little is known about the effects of exposure to the dust of hard fibre hemp from the leaf. The pharmacological observations of Nicholls
(1962) show that hemp and sisal dust contain a lower concentration of the smooth muscle contractor substance thought to produce the airway obstruction of byssinosis. On the other hand, Velvart, Stavrovská, and Hudáková (1964) consider that the respiratory disease of hemp workers is different from that of cotton workers in producing constitutional symptoms without the characteristic changes in ventilatory capacity during work. The literature is reviewed in more detail by Munt, Gauvain, Walford, and Schilling in this issue.

A West Indian woman with a history suggestive of byssinosis was admitted to the Queen Elizabeth Hospital, Birmingham, under the care of Professor Melville Arnott. She had been working for two years in the finishing section of a rope works using manila and St. Helena hemps and sisal. Both manila and St. Helena hemps are hard fibres. Investigation showed that it was unlikely that she had byssinosis, but, since her history suggested there might be others in the works with this 
disease, a survey was undertaken in June 1962.

The factory was convenient for study in that it had a separate section making wire ropes, and in this the workers were not exposed to natural fibre dusts, but otherwise their occupations were fairly similar.

\section{Process}

The process of rope making from hemp and sisal is divisible into two parts carried out in this factory on separate floors.

In the first part bales are opened, the hemp and sisal are cut into lengths and fed into hackling machines where they are broken up into constituent fibres and emerge as a skein for roving, which is also done on this floor. This part of the mill is referred to subsequently as the preparing section. All these operations are dusty, and the workers are exposed to the dust of both hemp and sisal.

A small group of workers preparing sisal tow were exposed to higher dust concentrations than the rest of the preparing section but to sisal alone. The short length fibres were initially shaken out into a pile on the floor before being loaded on to a conveyor taking them to a towing machine. Their results have been analysed separately.

The remainder of the rope-making process, carried out on the next floor, involved twisting the fibre, trimming the rope, and packing it. These processes have little dust and are referred to subsequently as finishing.

In the wire section the main operation was broadly similar to the twisting process in the natural fibre section, and the environmental temperature was similar. There was very little dust.

\section{Population}

The population on the day shift available for study comprised 89 women and 77 men using natural fibres and 36 men making wire ropes.

It had been intended to examine a sample from each section balanced for duration of exposure as well as age, sex, and race. This proved impossible since there were large differences in racial and sex distributions in the different sections of the mill. Further, the average duration of employment was much shorter in the preparing and sisal tow sections than elsewhere (Table 1).

The total number of people who could be adequately studied was atout 40 , and in the preparing section (excluding sisal tow) we selected 16 subjects likely to have been exposed to the highest dust concentration at work. Of the nine men, seven were from Pakistan and one was from Aden; two of the women were West Indian, and the rest were English.
TABLE 1

POPULATION STUDIED

\begin{tabular}{|c|c|c|c|c|c|}
\hline Section & Sex & No. & $\begin{array}{c}\text { Av. Age } \\
\text { (range) }\end{array}$ & $\begin{array}{c}\text { Av. Years } \\
\text { of Service } \\
\text { (range) }\end{array}$ & \begin{tabular}{|c|} 
No. Em- \\
ployed 2 \\
Years or Less
\end{tabular} \\
\hline \multirow[t]{2}{*}{ Preparing } & $\mathbf{M}$ & 9 & $\begin{array}{c}31 \cdot 2 \\
(24-43)\end{array}$ & $\begin{array}{c}2 \cdot 1 \\
(0 \cdot 5-3 \cdot 5)\end{array}$ & 5 \\
\hline & $\mathrm{F}$ & 7 & $\begin{array}{c}30 \cdot 1 \\
(18-56)\end{array}$ & $\begin{array}{c}3 \cdot 6 \\
(1 \cdot 5-8 \cdot 0)\end{array}$ & 4 \\
\hline Sisal tow & $\mathbf{M}$ & 6 & $\begin{array}{c}33 \cdot 7 \\
(25-40)\end{array}$ & $\begin{array}{c}1 \cdot 5 \\
(1-2 \cdot 5)\end{array}$ & 5 \\
\hline Finishing & $\mathbf{F}$ & 8 & $\begin{array}{c}27 \cdot 9 \\
(16-47)\end{array}$ & $\begin{array}{c}5.5 \\
(0.8-12)\end{array}$ & 3 \\
\hline Wire & $\mathbf{M}$ & 14 & $\begin{array}{c}38 \cdot 6 \\
(24-59)\end{array}$ & $\begin{array}{c}12.5 \\
(0 \cdot 5-40)\end{array}$ & 2 \\
\hline
\end{tabular}

In the sisal tow section, which was particularly dusty, we examined all the six workers: five were from Pakistan and one was from Aden.

Only women were employed in the finishing section, and we examined eight, all of whom were British, and also 14 of the men in the wire rope section, which included three men from Aden. In these two sections the subjects were selected from each part of the process, as the dust concentrations appeared fairly uniform and were low.

Although it cannot be assumed that this study is representative of the factory, it is unlikely that those with heavy dust exposure have been missed.

\section{Plan of Experiment}

On either a Monday or a Tuesday we saw each subject, first as soon as possible in the morning before appreciable exposure to dust, and again in the afternoon shortly before leaving, and on each occasion we measured various ventilatory capacity indices and the airways resistance. We could therefore estimate the changes during the day's work. All the subjects practised the tests on the previous Friday. On the Monday and Tuesday we also sampled airborne dust throughout the works but were not able to sample at the same site on the two days.

A month later another observer (R.S.F.S.) completed a modified form (Lammers, Schilling, and Walford, 1964) of the M.R.C. Questionnaire on Respiratory Symptoms on 41 of the 44 subjects.

Respiratory Function Tests.-The forced expiratory volume (F.E.V.1.0 ) and the forced vital capacity (F.V.C.) were measured either with a direct reading spirometer (McKerrow, McDermott, and Gilson, 1960) by one observer (J.C.G.), or else by the analysis of a forced expiratory spirogram produced 
from a Wedge spirometer* recording on a Mingograph spray writer $\dagger$ by a second observer (C.B.McK.). The spirograms obtained by the second method were analysed to give a number of different indices in common use to see whether any one was markedly superior to the others in demonstrating a change in ventilatory capacity during the day. Apart from the F.E.V. and F.V.C., the indices determined were the peak expiratory flow rate (P.F.R.), the forced mid-expiratory flow (F.E.F.25-75\%) of Leuallen and Fowler (1955), the average flow in the third quarter of the forced vital capacity (F.E.F.50-75\%) used by Franklin and Lowell (1961), and the flow rate at mid vital capacity (F.E.F.mid) described by Branscomb (1962). The terminology is that of Gandevia and Hugh-Jones (1957) supplemented where necessary by that recommended by the section on pulmonary function testing of the American College of Chest Physicians (1963).

Equal numbers of subjects were tested on the direct reading spirometer and on the Wedge spirometer and, so far as possible, they were balanced with regard to job and length of service. The average of the initial F.E.V.1.0 of the former group was 3.19 1. and of the latter 2.94 litres. The mean F.E.V. changes during the day by the two methods agreed within $0.01 \mathrm{l}$. and those of the F.V.C. within 0.03 litre. It is therefore justifiable to pool the results by the two methods.

One female preparer, indicated in the tables, was unable to produce a forced vital capacity. In all but one subject inspiratory resistance was measured using the rotary interrupter valve of Clements, Sharp, Johnson, and Elam (1959), and the results are expressed in arbitrary units (McKerrow, Roach, Gilson, and Schilling 1962).

Dust Measurements.-The mass of respirable and total airborne dust was measured using the Hexhlet and Soxhlet samplers respectively (Roach and

*Med. Science Electronics, Inc., St. Louis, Missouri, U.S.A. †Elema-Schönander AB, Stockholm, Sweden.
Schilling, 1960) sited four feet above the floor. Samples were obtained over a complete working shift from between two hackling machines, between two draw frames, near a towing machine, and near a twisting and edge trimming machine.

In the wire rope section, the absence of a suitably positioned power supply made it more convenient to sample the airborne dust using the Conicycle (Wolff and Roach, 1961), which has a size selection characteristic comparable with that of the Hexhlet.

\section{Results}

Dust Measurements.-Table 2 shows the dust concentrations. In the preparing section the sampler situated among the hackling machines showed a much higher concentration than that in the draw frame area, and unfortunately there was a considerable interchange of personnel between these two areas. In the mill as a whole, the dust concentrations

TABLE 2

DUST CONCENTRATIONS (mg./m. ${ }^{3}$ ) IN THE FACTORY (see text)

\begin{tabular}{l|c|c|c|c}
\hline \multicolumn{1}{c|}{ Section } & $\begin{array}{c}\text { Fine } \\
(<7 \mu)\end{array}$ & $\begin{array}{c}\text { Medium } \\
(7 \mu-2 \mathrm{~mm} .)\end{array}$ & $\begin{array}{c}\text { Coarse } \\
(>2 \mathrm{~mm} .)\end{array}$ & Total \\
\hline $\begin{array}{l}\text { Preparing: } \\
\text { Hackling } \\
\text { Draw frames }\end{array}$ & 0.47 & 0.67 & 0 & 1.10 \\
Sisal tow & 1.0 & 8.15 & 7.50 & 16.7 \\
Finishing & 0.30 & 0.47 & 0 & 0.77 \\
Wire & $0.29 *$ & - & - & 0.29 \\
\hline \multicolumn{4}{c}{ "Conicycle sample. }
\end{tabular}

can be considered low except in the sisal tow section, where the medium and coarse fractions of the dust were high relative to that elsewhere. The dust concentration in the wire section was very low, and a thermal precipitator sample showed almost all the particles to be below $1 \mu$ in size.

Tests of Lung Function.-The results of the F.E.V.1.0, F.V.C., F.E.V. \% and the inspiratory air-

TABLE 3

CHANGE IN F.E.V.1.0, F.V.C., AND AIRWAYS RESISTANCE DURING THE WORKING DAY

\begin{tabular}{|c|c|c|c|c|c|c|c|c|c|c|c|c|}
\hline \multirow{2}{*}{ Section } & \multirow{2}{*}{$\begin{array}{c}\text { No. of } \\
\text { Subjects }\end{array}$} & \multicolumn{3}{|c|}{ F.E.V.1.0 (1.) } & \multicolumn{3}{|c|}{ F.V.C. (1.) } & \multicolumn{2}{|c|}{ F.E.V. $\%$} & \multicolumn{3}{|c|}{ A.W.R. (units) } \\
\hline & & a.m. & p.m. & $\%$ Change & a.m. & p.m. & $\%$ Change & a.m. & p.m. & a.m. & p.m & $\%$ Change \\
\hline $\begin{array}{l}\text { Preparing } \\
\text { Sisal tow } \\
\text { Finishing } \\
\text { Wire }\end{array}$ & $\begin{array}{r}16 \\
6 \\
8 \\
14\end{array}$ & $\begin{array}{l}3.15 \\
3.03 \\
2.64 \\
3.22\end{array}$ & $\begin{array}{l}3 \cdot 08 \dagger \\
2 \cdot 83 \ddagger \\
2 \cdot 67 \\
3 \cdot 32 \S\end{array}$ & $\begin{array}{l}-2.2 \\
-6.6 \\
+1.1 \\
+3.1\end{array}$ & $\begin{array}{l}3.61^{*} \\
3.48 \\
2.92 \\
3.98\end{array}$ & $\begin{array}{l}3.57 * \\
3.33 \S \\
3.0 \\
4.04\end{array}$ & $\begin{array}{l}-1 \cdot 1^{*} \\
-4 \cdot 3 \\
+2 \cdot 7 \\
+1 \cdot 5\end{array}$ & $\begin{array}{l}90.6 \\
86.8 \\
89 \cdot 2 \\
80.7\end{array}$ & $\begin{array}{l}89 \cdot 4 \\
84.8 \\
88.1 \\
82.5\end{array}$ & $\begin{array}{l}0 \cdot 755^{*} \\
0.573 \\
1 \cdot 152 \\
0.787\end{array}$ & $\begin{array}{l}0.725^{*} \\
0.604 \\
1.131 \\
0.775\end{array}$ & $\begin{array}{r}-4.0 \\
+5.4 \\
-1.8 \\
-1.5\end{array}$ \\
\hline
\end{tabular}

*Results for 15 subjects.

tChange from a.m. values significant at $0.1 \%$ level.

§̧Change from a.m. values significant at $5 \%$ level. 
TABLE 4

CHANGE IN PEAK FLOW RATE AND OTHER DERIVATIVES OF THE FORCED EXPIRATORY SPIROGRAM DURING THE WORKING DAY

\begin{tabular}{|c|c|c|c|c|c|c|c|c|c|c|c|c|c|}
\hline \multirow{2}{*}{ Section } & \multirow{2}{*}{$\begin{array}{l}\text { No. of } \\
\text { Subjects }\end{array}$} & \multicolumn{3}{|c|}{$\begin{array}{c}\text { Peak Flow Rate } \\
(1 . / \mathrm{min} .)\end{array}$} & \multicolumn{3}{|c|}{$\begin{array}{c}\text { F.E.F }{ }_{(1 . / \mathrm{sec} .)}{ }^{25} \text { per cent } \\
\end{array}$} & \multicolumn{3}{|c|}{$\begin{array}{c}\text { F.E.F.50-75 per cent } \\
(1 . / \mathrm{sec} .)\end{array}$} & \multicolumn{3}{|c|}{$\underset{(1 . / \mathrm{sec} .)}{\text { F.E.F.mid }}$} \\
\hline & & a.m. & p.m. & $\begin{array}{c}\% \\
\text { Change }\end{array}$ & a.m. & p.m. & $\begin{array}{c}\% \\
\text { Change }\end{array}$ & a.m. & p.m. & $\begin{array}{c}\% \\
\text { Change }\end{array}$ & a.m. & p.m. & $\begin{array}{c}\% \\
\text { Change }\end{array}$ \\
\hline $\begin{array}{l}\text { Preparing } \\
\text { Sisal tow } \\
\text { Finishing } \\
\text { Wire }\end{array}$ & $\begin{array}{l}8^{*} \\
3 \\
4 \\
7\end{array}$ & $\begin{array}{l}490 \\
558 \\
294 \\
496\end{array}$ & $\begin{array}{l}430+ \\
460 \dagger \\
295 \\
522\end{array}$ & $\begin{array}{r}-12.2 \\
-17.6 \\
+0.3 \\
+5.2\end{array}$ & $\begin{array}{l}4 \cdot 94 \\
4 \cdot 25 \\
3 \cdot 25 \\
3 \cdot 97\end{array}$ & $\begin{array}{l}4 \cdot 23 \dagger \\
4 \cdot 01 \\
3 \cdot 18 \\
4 \cdot 24\end{array}$ & $\begin{array}{r}-14.4 \\
-5.6 \\
-2.2 \\
+6.8\end{array}$ & $\begin{array}{l}3 \cdot 86 \\
3 \cdot 22 \\
2 \cdot 66 \\
2 \cdot 91\end{array}$ & $\begin{array}{l}3 \cdot 33 \dagger \\
3.02 \\
2 \cdot 48 \\
3 \cdot 11\end{array}$ & $\begin{array}{r}-13.7 \\
-6.2 \\
-6.8 \\
+6.9\end{array}$ & $\begin{array}{l}5 \cdot 05 \\
4 \cdot 57 \\
3 \cdot 33 \\
4 \cdot 42\end{array}$ & $\begin{array}{l}4 \cdot 59 \dagger \\
4 \cdot 10_{\ddagger}^{+} \\
3 \cdot 24 \\
4 \cdot 48\end{array}$ & $\begin{array}{r}-9 \cdot 1 \\
-10.3 \\
-2.7 \\
+1.4\end{array}$ \\
\hline
\end{tabular}

* Four were women; F.E.F. indices from seven subjects.

tChange from a.m. values significant at $1 \%$ level.

$\ddagger$ Change from a.m. values significant at $5 \%$ level.

TABLE 5

CHANGE IN F.E.V.1.0 AND F.V.C. DURING THE WORKING DAY IN THOSE SUBJECTS SHOWN IN TABLE 4

\begin{tabular}{|c|c|c|c|c|c|c|c|c|c|}
\hline \multirow{2}{*}{ Section } & \multirow{2}{*}{$\begin{array}{l}\text { No. of } \\
\text { Subjects }\end{array}$} & \multicolumn{3}{|c|}{ F.E.V. $\cdot_{1 \cdot 0}(1)}$. & \multicolumn{3}{|c|}{ F.V.C. (1.) } & \multicolumn{2}{|c|}{ F.E.V. $\%$} \\
\hline & & a.m. & p.m. & $\%$ Change & a.m. & p.m. & $\%$ Change & a.m. & p.m. \\
\hline $\begin{array}{l}\text { Preparing } \\
\text { Sisal tow } \\
\text { Finishing } \\
\text { Wire }\end{array}$ & $\begin{array}{l}8 \\
3 \\
4 \\
7\end{array}$ & $\begin{array}{l}2 \cdot 93 \\
3 \cdot 24 \\
2 \cdot 31 \\
3 \cdot 17\end{array}$ & $\begin{array}{l}2.84 \\
3.06 \\
2 \cdot 37 \\
3 \cdot 30\end{array}$ & $\begin{array}{l}-3.1 \\
-5.6 \\
+2.6 \\
+4.1\end{array}$ & $\begin{array}{l}3.44^{*} \\
3.64 \\
2.63 \\
3.95\end{array}$ & $\begin{array}{l}3 \cdot 36^{*} \\
3 \cdot 51^{\ddagger} \\
2 \cdot 77^{\dagger} \\
4 \cdot 04\end{array}$ & $\begin{array}{l}-2 \cdot 3^{*} \\
-3 \cdot 6 \\
+5 \cdot 3 \\
+2 \cdot 3\end{array}$ & $\begin{array}{l}91 \cdot 3^{*} \\
88 \cdot 7 \\
86 \cdot 6 \\
80 \cdot 1\end{array}$ & $\begin{array}{l}87 \cdot 7 * \\
87 \cdot 2 \\
84 \cdot 6 \\
81 \cdot 6\end{array}$ \\
\hline
\end{tabular}

* Results from seven subjects.

tChange from a.m. value significant at $1 \%$ level.

$\ddagger$ Change from a.m. value significant at $5 \%$ level.

ways resistance measurements are given in Table 3. There was a small fall in both F.E.V.1.0 and F.V.C. in the preparing section, and a greater one in sisal tow. This contrasts with a small rise during the day in both tests in the finishing and wire sections.

The inspiratory airways resistance shows a fall in all sections except that of sisal tow, in which there is a small rise, but none of the changes is statistically significant.

The additional information given by the other derivatives of the forced expiratory spirogram are shown in Table 4 for those subjects in whom it was recorded by the Wedge spirometer.

In general, the tests followed the same pattern as the F.E.V.1.0, namely, a fall during the day in the preparing section and also in those working in sisal tow, whereas there was little fall or even a small rise in those working in the finishing or in the wire sections. In the preparing section, all the indices fell significantly whereas in sisal tow the change in the peak flow rate and F.E.V. .mid $_{\text {are significant. Table } 5}$ gives results for the F.E.V.1.0 and F.V.C. for the same subjects and it shows that, unlike the results of the whole group (Table 3), there is now only one significant fall. The significant rise in the F.V.C. in the finishing section is due to the chance selection of four subjects with very similar rises in F.V.C., whereas in the main sample (Table 3) two of the eight showed falls in F.V.C. during the day.

Further evidence on the relative sensitivity of the tests was obtained by an analysis of variance of the 
TABLE 7

RESULTS OF THE QUESTIONNAIRE ON RESPIRATORY SYMPTOMS

\begin{tabular}{|c|c|c|c|c|c|c|c|c|}
\hline \multirow[b]{2}{*}{ Section } & \multirow[b]{2}{*}{ Sex } & \multicolumn{2}{|c|}{ Smoking } & \multirow{2}{*}{$\begin{array}{c}\text { Persistent } \\
\text { Cough } \\
(5)^{*}\end{array}$} & \multirow{2}{*}{$\begin{array}{l}\text { Persistent } \\
\text { Phlegm } \\
{(9)^{*}}^{-1}\end{array}$} & \multirow{2}{*}{$\begin{array}{c}\text { Chest } \\
\text { Illness } \\
(21)^{*}\end{array}$} & \multirow{2}{*}{$\begin{array}{l}\text { Smokers } \\
\text { with Cough } \\
\text { or Phlegm }\end{array}$} & \multirow{2}{*}{$\begin{array}{c}\text { Symptoms } \\
\text { of } \\
\text { Byssinosis }\end{array}$} \\
\hline & & Smokers & $\begin{array}{c}\text { Non and } \\
\text { Ex-smokers }\end{array}$ & & & & & \\
\hline $\begin{array}{l}\text { Preparing } \\
\text { Sisal tow } \\
\text { Finishing } \\
\text { Wire }\end{array}$ & $\begin{array}{l}\mathbf{M} \\
\mathbf{F} \\
\mathbf{M} \\
\mathbf{F} \\
\mathbf{M}\end{array}$ & $\begin{array}{l}6 \\
1 \\
5 \\
1 \\
9\end{array}$ & $\begin{array}{l}3 \\
5 \\
1 \\
5 \\
5\end{array}$ & $\begin{array}{l}1 \\
4 \\
0 \\
0 \\
3\end{array}$ & $\begin{array}{l}1 \\
2 \\
0 \\
0 \\
3\end{array}$ & $\begin{array}{l}0 \\
0 \\
0 \\
0 \\
0\end{array}$ & $\begin{array}{l}1 \\
0 \\
0 \\
0 \\
3\end{array}$ & $\begin{array}{l}0 \\
0 \\
0 \\
0 \\
0\end{array}$ \\
\hline
\end{tabular}

*The figures in brackets refer to the question numbers in the M.R.C. Questionnaire (1960).

TABLE 8

VENTILATORY FUNCTION CHANGES DURING THE WORKING DAY IN THOSE WITH AND WITHOUT COUGH AND SPUTUM

\begin{tabular}{|c|c|c|c|c|c|c|c|c|c|c|c|c|c|c|c|}
\hline \multirow{2}{*}{ Section } & \multirow{2}{*}{$\operatorname{Sex}$} & \multirow{2}{*}{$\begin{array}{l}\text { Cough } \\
\text { and } \\
\text { Sputum }\end{array}$} & \multirow{2}{*}{ No. } & \multirow{2}{*}{$\begin{array}{c}\text { Average } \\
\text { Age }\end{array}$} & \multicolumn{3}{|c|}{ F.E.V.1.0 $(1)}$. & \multicolumn{3}{|c|}{ F.V.C. (1.) } & \multicolumn{2}{|c|}{ F.E.V. $\%$} & \multicolumn{3}{|c|}{ Insp. A.W.R. (units) } \\
\hline & & & & & a.m. & p.m. & $\begin{array}{c}\% \\
\text { Change }\end{array}$ & a.m. & p.m. & Change & a.m. & p.m. & a.m. & p.m. & $\begin{array}{c}\% \\
\text { Change }\end{array}$ \\
\hline & $\mathrm{F}$ & \pm & $\begin{array}{l}2 \\
4\end{array}$ & $\begin{array}{l}50 \\
23\end{array}$ & $\begin{array}{l}1 \cdot 57 \\
3 \cdot 19\end{array}$ & $\begin{array}{l}1 \cdot 49 \\
3 \cdot 18\end{array}$ & $\begin{array}{l}-5 \cdot 1 \\
-0 \cdot 3\end{array}$ & $\begin{array}{l}2.00 \dagger \\
3.55\end{array}$ & $\begin{array}{l}1.93 \dagger \\
3.62\end{array}$ & $\begin{array}{l}-3.5 \dagger \\
+2.0\end{array}$ & $\begin{array}{l}86.0 \dagger \\
90.4\end{array}$ & $\begin{array}{l}79 \cdot 0 \dagger \\
88 \cdot 1\end{array}$ & $\begin{array}{l}1.014 \\
0.882\end{array}$ & \begin{tabular}{|l|}
0.866 \\
0.842
\end{tabular} & $\begin{array}{r}-14.6 \\
-4.5\end{array}$ \\
\hline
\end{tabular}

* Results on seven subjects.

† Result on one subject.

ness on Mondays or appeared to be suffering from chronic bronchitis (defined as persistent phlegm and chest illness causing absence from work for at least seven days in the last three years).

In a further group of 21 workers employed in the rope works for at least 10 years, no one gave a history of chest tightness on Mondays.

The one man in the preparing section with persistent cough and phlegm was a smoker of 10 cigarettes per day who had worked in the factory for less than one year. Among the six women in the preparing section who answered the questionnaire, four had a persistent cough and, of these, two had in addition persistent phlegm. All were non-smokers, but three of the four had worked between four and a half and eight years in the factory. It is perhaps of interest that among the women in the finishing section there were no symptoms in spite of a longer average length of service.

There were no symptoms among the men in the sisal tow section, but the average length of service is very short.

In the wire section, three men had symptoms of persistent cough and sputum: all were smokers of 10 or more cigarettes per day who had worked in the factory three, 25 , and 40 years.

Table 8 shows no clear relation between the change in ventilatory function during the day and the presence or absence of cough and sputum. However, the numbers of subjects with symptoms are very small to establish any relationship.

Of the 41 subjects who answered the questionnaire, 22 were smokers of 10 or more cigarettes per day and 19 were either non-smokers or ex-smokers. The numbers of subjects are again very small, and there was no clear relationship between smoking habit and change in ventilatory function during the working day.

\section{Discussion}

Although there were no complaints of chest tightness on Mondays among those workers questioned, there was a significant deterioration in ventilatory function during the day's work in the dustier parts of the mill.

The significant increase in the F.E.V. in the wire section is unexplained, although it may in part at least be due to a considerable improvement during the day in those complaining of cough and sputum. Such an increase is known to occur in hospital patients with bronchitis after clearance of sputum (Lewinsohn, Capel, and Smart, 1960), and a similar effect has been noted in surveys of cotton workers.

The largest functional changes were in the sisal tow section where total, medium, and fine dust concentrations were by far the highest. There were large differences in the dust concentrations in 
different parts of the preparing section, but as subjects were selected among those in the most dusty parts it is likely that their exposure followed the higher of the two samples. If this is true, then the change in F.E.V. roughly follows the fine or medium dust concentration, and more detailed study would be needed to establish any difference in the response to these two size fractions.

The forced vital capacity showed a significant fall in the sisal tow section alone, but the F.E.V./F.V.C. ratio was little changed during the day in any section.

The inspiratory airways resistance by the interrupter method did not change significantly, presumably because of the wide scatter in this test in individual subjects. The sensitivity of the interrupter method is less than that of the body plethysmograph (Lloyd and Wright, 1963).

The derivatives of the forced expiratory spirogram obtained with the Wedge spirometer on half the subjects followed those of the F.E.V., but the percentage changes were usually larger, and in the small number of subjects in whom these indices were calculated, it seemed that the peak flow rate, the F.E.F. ${ }_{25-75 \%}$, the F.E.F.50-75\%, and the F.E.F.mid may be somewhat more sensitive measures of the acute changes in ventilatory capacity following inhalation of this dust than the forced expiratory volume and forced vital capacity. But the findings in this small group may not be of general application, and study on a larger group, particularly of cotton workers, would be of interest.

In considering the results of the questionnaire on respiratory symptoms and smoking in relation to the respiratory function tests, it is necessary to emphasize that the number of subjects is small, and that language difficulties probably reduced the accuracy of the answers. It may be that in this group the function tests give a better picture of the effects of dust exposure than the questionnaire, but the complete absence of chest tightness on Mondays makes it unlikely that the environment was producing an effect comparable with that found in a dusty card room of a cotton mill.

The finding of a fall in ventilatory capacity during the day in the dusty sections of the factory, but with no symptoms of chest tightness on Mondays, agrees with that of the survey of rope workers by Munt et al. also reported in this Journal.

We thank Mr. C. E. Rossiter for advice on the statistical analysis, and Miss Ann Hart and Mrs. Kathleen Morse for technical assistance. We are grateful to the management of the factory and to the subjects who took part for their willing co-operation; also to Professor W. Melville Arnott and Dr. M. D. Kipling who brought the original suspected case to our notice.

\section{REFERENCES}

American College of Chest Physicians (1963). Dis. Chest, 43, 214. Branscomb, B. (1962). Amer. Rev. resp. Dis., 86, 697.

Clements, J. A., Sharp, J. T., Johnson, R. P., and Elam, J. O. (1959). J. clin. Invest., 38, 1262.

Elwood, P. C., Pemberton, J., Merrett, J. D., Carey, G. C. R. McAulay, I R (1965). Brit J industr Med 22 27.

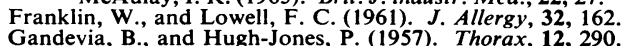

Gandevia, B., and Hugh-Jones, P. (1957). Thorax, 12, 290. C. B., and Schilling, R. S. F. (1962). Brit. J. industr. Med., 19, 9 .'

Lammers, B., Schilling, R. S. F., and Walford, J. (1964). Ibid., 21, 124

Leuallen, E. C., and Fowler, W. S. (1955). Amer. Rev. Tuberc., 72, 783.

Lewinsohn, H. C., Capel, L. H., and Smart, J. (1960). Brit. med. J.,

Lloyd, T. C. Jr., and Wright, G. W. (1963). Amer. Rev. resp. Dis., 87, 529.

Mair, A., Smith, D. H., Wilson, W. A., and Lockhart, W. (1960) Brit. J. industr. Med., 17, 272.

McKerrow, C. B., McDermott, M., and Gilson, J. C. (1960). Lancet, $1,149$.

Roach, S. A., Gilson, J. C., and Schilling, R. S. F. (1962). Brit. J. industr. Med., 19, 1

Medical Research Council (1960). Brit. med. J., 2, 1665.

Munt, D. F., Gauvain, S., Walford, J., and Schilling, R. S. F. (1965) D. F., Gauvain, S., Writ. J. industr. Med., 22, 196.

Nicholls, P. J. (1962). Ibid., 19, 33.

Ramazzini, B. (1713). De Morbis Artificum. Diseases of Workersthe Latin text of 1713. Revised, with translation and notes by

Roach, S. A and Schilling, R. S. F (1960) Brit. J industr. Med. 17,1 .

Schilling, R. S. F., Hughes, J. P. W., Dingwall-Fordyce, I., and Gilson, J. C.'(1955). Ibid., 12, 217

Smiley, J. A. (1961). Ibid., 18, 1.

Stott, H. (1958). Ibid., 15, 23.

Wolf, H. S., and Roach, S. A. (1961). In Inhaled Particles and Vapours, ed. C. N. Davies, pp. 460-464. Pergamon Press, Oxford.

Velvart, J., Stavrovská, O., and Hudáková, G. (1964). Pracov. Lék, 